NBER WORKING PAPER SERIES

\title{
ELECTRICITY PRICE DISTRIBUTIONS IN FUTURE RENEWABLES-DOMINANT POWER GRIDS AND POLICY IMPLICATIONS
}

\author{
Dharik S. Mallapragada \\ Cristian Junge \\ Cathy Xun Wang \\ Johannes Pfeifenberger \\ Paul L. Joskow \\ Richard Schmalensee \\ Working Paper 29510 \\ http://www.nber.org/papers/w29510 \\ NATIONAL BUREAU OF ECONOMIC RESEARCH \\ 1050 Massachusetts Avenue \\ Cambridge, MA 02138 \\ November 2021
}

MIT Energy Initiative Future of Storage Study (no grant numbers) Acknowledgment: We are indebted to the MIT Energy Initiative's Future of Storage Study for research support and intellectual stimulation and, in particular to Howard Gruenspecht for valuable comments and conversations. Paul Joskow discloses that he is on the Board of Directors of Exelon Corporation, a public utility holding company. Johannes Pfeifenberger discloses that he is employed as a Principal at The Brattle Group, a consulting firm. Neither Exelon nor The Brattle Group had any involvement with the preparation of this paper or the underlying research. The views expressed herein are those of the authors and do not necessarily reflect the views of the National Bureau of Economic Research.

NBER working papers are circulated for discussion and comment purposes. They have not been peer-reviewed or been subject to the review by the NBER Board of Directors that accompanies official NBER publications.

(C) 2021 by Dharik S. Mallapragada, Cristian Junge, Cathy Xun Wang, Johannes Pfeifenberger, Paul L. Joskow, and Richard Schmalensee. All rights reserved. Short sections of text, not to exceed two paragraphs, may be quoted without explicit permission provided that full credit, including (C) notice, is given to the source. 
Electricity Price Distributions in Future Renewables-Dominant Power Grids and Policy Implications Dharik S. Mallapragada, Cristian Junge, Cathy Xun Wang, Johannes Pfeifenberger, Paul L.

Joskow, and Richard Schmalensee

NBER Working Paper No. 29510

November 2021

JEL No. L11,L51,L94,Q41,Q42,Q49

\section{ABSTRACT}

Future electricity systems with tight constraints on carbon emissions will rely much more on wind and solar generation, with zero marginal cost, than today. We use capacity expansion modelling of Texas in 2050 to illustrate wholesale price distributions in future energy-only, carbon-constrained grids without price caps under a range of technology/system assumptions. Tightening carbon emissions constraints dramatically increases the frequency of very low prices. The frequency of high prices also increases, and all resources earn the bulk of their energy market revenues in relatively few hours. The presence of demand response, long-duration energy storage, dispatchable low-carbon generation, or a robust market for hydrogen for non-electricity use (and for energy storage) weakens but does not undo these results. Financial instruments to hedge price volatility will consequently be more costly and it is likely that we will need to redesign capacity remuneration mechanisms to provide adequate incentives for optimal investment in VRE generation and, particularly, storage. In order to encourage economy-wide electrification, the marginal retail price of electricity should be low whenever the wholesale price is low. With automated control of demand via demand response contracts, the risks of price volatility faced by retail customers can be mitigated without sacrificing efficiency. To encourage economy-wide electrification, the marginal retail price of electricity should be low when the wholesale spot price is low. We discuss ways of reducing consumers' risk in this world while providing adequate investment incentives.

Dharik S. Mallapragada

MIT Energy Initiative

Building E19

MIT

Cambridge, MA 02139

dharik@mit.edu

Cristian Junge

MIT Energy Initiative

Building E19

MIT

Cambridge, MA 02139

cjunge@mit.edu

Cathy Xun Wang

MIT Energy Initiative

Building E19

MIT

Cambridge, MA 02139

cathyxw@mit.edu
Johannes Pfeifenberger

Principal, The Brattle Group

Hannes.Pfeifenberger@brattle.com

Paul L. Joskow

Department of Economics, E52-414

MIT

77 Massachusetts Avenue

Cambridge, MA 02139

and NBER

pjoskow@mit.edu

Richard Schmalensee

MIT Sloan School of Management

100 Main Street, E62-525

Cambridge, MA 02142

and NBER

rschmal@mit.edu 


\section{Introduction}

Modeled pathways for energy system decarbonization by mid-century indicate an expanded role for electricity in final energy demand, coupled with the decarbonization of electricity supply through increasing generation from variable renewable energy (VRE) sources, particularly wind and solar[1-3]. For example, in the net-zero by 2050 scenario proposed by the International Energy Agency (IEA), electricity as a share of global final energy consumption is projected to increase from $20 \%$ in 2020 to $50 \%$ by 2050 , while wind and solar provide $70 \%$ of total electricity generation in 2050 [2]. The dominance of VRE-based power generation in energy system-wide studies is also aligned with more granular power sector assessments [4-11], that use cost-minimizing (or welfare-maximizing) capacity expansion models (CEMs) to identify key attributes of efficient, deeply decarbonized electricity systems. State-of-art CEMs[12-16] evaluate the cost-optimal investment and intra-annual operation of modeled power systems, and thus are in principle able to highlight the implications of temporal variability in electricity demand and in VRE resource availability under alternative assumptions on technologies' cost, performance and availability, on electricity demand, and on policy. CEMs are often formulated as linear programs with perfect foresight and constant returns to scale; under these and other standard assumptions, CEMs can approximate outcomes of equilibria in competitive markets. Hence, CEMs can be used to understand the impact of policy and technology drivers on the distribution of the marginal value of electrical energy (which we take as a good approximation of the wholesale spot electricity price in an energy-only market like ERCOT), which is retrieved from the models as the shadow price on the supply/demand constraint at each operating time step (see note S1.1 in the Appendix). In this Perspective, we summarize what CEM studies of efficient, deeply decarbonized electricity systems tell us about the probability distributions of wholesale electricity prices under various 
assumptions, as well as its broader implications for cost recovery of investments in the power sector and for the design of retail electricity tariffs to support efficient economy-wide decarbonization via electrification.

Wholesale price formation and system operation in competitive electricity markets are generally governed by the well-documented principle of least-cost economic dispatch [17]. Per this approach, at any instant the resource with the highest marginal cost (i.e. the cost of producing an incremental unit of electricity) among all operating generators or when generating capacity is fully utilized, a higher price needed to balance supply and demand (scarcity pricing), determines the market clearing electricity price. Thermal power plants dominate the generation portfolio in most power systems today. They are dispatchable (i.e., their outputs can be varied within limits by the operator) and have positive marginal costs. VRE generators, however, use no fuel inputs and thus have near zero marginal operating costs. The marginal cost of supply from energy storage systems is generally set by opportunity costs rather physical operating costs and hence can vary substantially over time. Thus, a shift from primary reliance on dispatchable thermal generators to primary reliance on VRE generators with a greater role for storage seems a priori likely to change the probability distributions of wholesale electricity prices.

CEMs can be used to understand the impacts on the distribution of wholesale electricity prices of increasing VRE penetration and increasing energy storage under the condition of full cost recovery for all assets (resulting from the deterministic LP formulation; see note S1.2 on why we preferred CEMs over production cost models) [10]. Despite the many CEM studies focused on deep decarbonization of electricity systems $[4,7,11,18]$, few studies actually document the implied wholesale electricity price distributions. Several CEM studies that do discuss electricity prices [10,19-22], including our own, find that wholesale electricity price distributions under low-carbon 
high-VRE scenarios are likely to have many more hours of very low prices (corresponding to periods of high VRE availability relative to load) than are observed today in wholesale electricity markets (see note S1.3) and more hours of very high prices, approaching the value of lost load (corresponding to periods of high net load i.e. load minus VRE generation). The extent of both these effects is dependent on many factors, notably, a) the stringency and type of policy encouraging low-carbon generation, b) the assumed resource adequacy requirements, if any, c) the temporal resolution of grid operations modeled, which is shown to be important to capture VRE resource and load variations $[23,24]$, c) the cost assumptions and availability of technologies like VRE, storage, low-carbon dispatchable generation and d) the cost and availability of demand response and demand flexibility. The impact of some of these factors on the distribution of simulated future wholesale electricity prices will be explored quantitatively below.

Recently, a few papers have suggested that instances of low wholesale prices could be infrequent and prices may never approach the value of lost load, if a large fraction of future energy demand could be met either by electricity or by switching to carbon-free chemical energy carriers (referred here on as "synthetic fuels"). Potential consumers capable of this sort of demand flexibility cited in the literature include district heating systems, plug-in hybrid electric vehicles and dual-fuel boilers in industrial settings[5,25,26]. In deeply decarbonized energy systems, however, the availability and cost of carbon-free synthetic fuels that can substitute for electricity at scale is highly uncertain. Moreover, if electricity is consumed in producing these synthetic fuels, which is likely for hydrogen-derived synthetic fuels [27], then the cost and availability of synthetic fuel may vary over time, which is inconsistent with the constant cost and availability assumption made by some studies $[8,26]$. As we show later, incorporating the investment and operation of the supply chain of synthetic fuels, including production, storage and utilization, within a CEM 
reduces instances of low and high electricity prices (by improving VRE and storage utilization) but does not eliminate them.

\section{Factors impacting electricity price distributions under deep decarbonization}

To quantify the impact of the above-mentioned factors on wholesale electricity price distributions, we used the GenX model to simulate deeply decarbonized electricity systems under a number of scenarios, described in Table 1. An open-source CEM [16], GenX, includes representation of various supply and demand-side resources, including energy storage with independent discharging and charging power capacities and energy storage capacity, demand flexibility, demand response, and use of hydrogen for non-electric end-uses. Flexible demand resources can temporally shift their energy consumption to some extent, with examples including electric vehicle charging and advancing or delaying heating or cooling of buildings. Demand response resources, on the other hand, can forgo consumption entirely when the electricity price is high.

The case study evaluated using the GenX model here is based on projected load and VRE resource availability in Texas in 2050. Texas is represented as a single transmission zone with greenfield conditions reflecting the retirement of the existing fleet by 2050 . The model is configured with hourly resolution of grid operations spanning 7 years (61,314 hours) and an approximation of a competitive energy-only wholesale market resembling the market the Electric Reliability Council of Texas (ERCOT) now operates in most of the state. We assume prices can approach the value of lost load (set at $\$ 50,000 / \mathrm{MWh}$ in our simulations to ensure high reliability outcomes). As in ERCOT, no other resource adequacy requirements, either at the annual or hourly timescales, are enforced, so generators and storage facilities are fully remunerated through energy 
market revenues. The model uses assumed annual electricity demand data for 2050 from the highelectrification scenario developed by the National Renewable Energy Laboratory (NREL) for its 2018 Electrification Futures (EFS) study [28]. The demand data was assumed to be same for all seven years of modeled grid operations and includes a peak load of $151 \mathrm{GW}$ and annual consumption of 715 TWh, PV and Wind resource availability were represented using a discretized supply curve approach, described elsewhere[4], that is developed based on available wind and solar resource databases from NREL. Technology cost assumptions are sourced mostly from the 2020 edition of the NREL annual technology database [29]. Further documentation of data inputs and model representation is discussed in Table S 1 - Table S 5 in the SI and in Table 1 below.

Table 1. Scenario groupings evaluated via the GenX model for various $\mathrm{CO}_{2}$ emissions constraints in this work.

\begin{tabular}{|c|c|}
\hline $\begin{array}{l}\text { Scenario } \\
\text { grouping }\end{array}$ & Description \\
\hline Base Case & $\begin{array}{l}\text { Reference assumptions and conditions; Li-ion as the only energy storage } \\
\text { technology, along with following generation resources: wind, solar PV, } \\
\text { natural gas (NG) combined cycle gas turbine (CCGT) with and without } \\
\text { carbon capture and sequestration (CCS) and open cycle gas turbine (OCGT). } \\
\text { Assumed natural gas fuel price: } \$ 4.16 / \mathrm{MMBtu} \text { - see section } \mathrm{S} 1 \text {. }\end{array}$ \\
\hline Base + RFB & $\begin{array}{l}\text { Inclusion of low-cost energy storage with estimated cost and performance } \\
\text { characteristics for redox flow battery (RFB) systems - see Table S } 2\end{array}$ \\
\hline $\begin{array}{l}\text { Base }+ \text { RFB }+ \\
\text { Thermal } \\
\text { storage }\end{array}$ & $\begin{array}{l}\text { Inclusion of low-cost long-term energy storage with estimated cost and } \\
\text { performance estimates for thermal energy storage systems - see Table S } 2\end{array}$ \\
\hline Base + DF & $\begin{array}{l}\text { Allowing a pre-specified fraction of flexible demand from EV charging and } \\
\text { buildings to be temporally flexible at no incremental cost, per the } \\
\text { assumptions from NREL electrification futures study [28], and summarized } \\
\text { in Table S } 4 \text {. }\end{array}$ \\
\hline Base+ DR & $\begin{array}{l}\text { Stylized representation of demand response, per the structure described } \\
\text { elsewhere [7]. Up to } 25 \% \text { of hourly load can be shed with varying marginal } \\
\text { costs for each incremental } 5 \% \text { of load, with the most expensive segment } \\
\text { priced at } 70 \% \text { of value of lost load (VoLL, } \$ 50,000 / \mathrm{MWh} \text { ) and the least } \\
\text { expensive segment priced at } 5 \% \text { of value of lost load (See Table S 5). Further } \\
\text { load shedding is possible at the price equal to VoLL. }\end{array}$ \\
\hline Base + RNG & $\begin{array}{l}\text { Scenario meant to approximate the availability of renewable natural gas } \\
\text { (RNG) or hydrogen for dispatchable power generation used in other studies } \\
\text { [8]. Modeled as carbon-neutral fuel with a cost of \$20/MMBtu via an OCGT } \\
\text { with heat rate the same as that of conventional NG based OCGT and capital } \\
\text { cost that } 120 \% \text { of the NG OCGT capital cost. }\end{array}$ \\
\hline
\end{tabular}




\begin{tabular}{|c|l|}
\hline $\begin{array}{c}\text { Base }+\mathrm{RFB}+ \\
\mathrm{np}-\mathrm{H} 2 @ \$ 2 \\
\text { or 10/kg }\end{array}$ & $\begin{array}{l}\text { Representation of exogenous } \mathrm{H}_{2} \text { demand } \text { outside the power sector }(19.7 \\
\mathrm{GW} / 2) \text { that can be met via a combination of electrolysis, hydrogen storage/ } \\
\text { discharging as well as from non-power based } \mathrm{H}_{2} \text { sources with zero process }\end{array}$ \\
$\begin{array}{l}\mathrm{CO}_{2} \text { emissions with a production cost of } \$ 2 \text { or } \$ 10 / \mathrm{kg}-\text { see Figure } \mathrm{S} 1 \text { and } \\
\text { section } \mathrm{S} 5 \text { for detailed assumptions. Also includes RFB storage in addition to } \\
\text { Li-ion storage in the power sector. }\end{array}$ \\
\hline
\end{tabular}

Impact of technology availability and sector-coupling on power system outcomes

Figure 1 highlights key system outcomes under two $\mathrm{CO}_{2}$ emissions intensity constraints $\left(5 \mathrm{gCO}_{2} / \mathrm{kWh}\right.$ and $\left.1 \mathrm{gCO}_{2} / \mathrm{kWh}\right)$ for the eight scenarios defined in Table 1 . Texas emissions in 2018 were $449 \mathrm{gCO} 2 / \mathrm{kWh}$, so achieving a grid emissions intensity of $5 \mathrm{gCO}_{2} / \mathrm{kWh}$ or 1 $\mathrm{gCO}_{2} / \mathrm{kWh}$ would amount to a $98.9 \%$ or $99.8 \%$ reduction, respectively. A few main observations should be noted from Figure 1. First, for the same $\mathrm{CO}_{2}$ emissions constraint, availability of additional flexible resources relative to the base case, either on the supply side via dispatchable renewable generation (RNG) or long-duration energy storage (LDES), or on the demand-side via demand flexibility (DF) or demand response (DR), reduces VRE curtailment and thus improves VRE capacity utilization. This contributes to reducing the system average cost of electricity (SCOE). Second, increasing stringency of $\mathrm{CO}_{2}$ emissions limits from $5 \mathrm{gCO}_{2} / \mathrm{kWh}$ to $1 \mathrm{gCO}_{2} / \mathrm{kWh}$ results in greater VRE curtailment as well as an increase in SCOE across all the scenarios, ranging from 12\% (Base + DF) to 3\% (Base +RFB+ np-H2 @ \$2/kg).

Third, the availability of electricity storage technologies with low energy capital cost, represented here by redox flow battery (RFB) technology, thermal storage and hydrogen, increases the value of VRE generation and reduces the role for dispatchable gas generation. The hydrogen scenarios modeled here highlight the potential opportunity to share hydrogen-related assets, namely the electrolyzer used to produce hydrogen and storage, to serve both the power sector and external hydrogen demand simultaneously. This is effectively a special case of 
demand flexibility, since the use of electricity to produce hydrogen via electrolysis can be flexibly scheduled because hydrogen can be stored at relatively low energy capital cost, even though external hydrogen demand is modeled to be constant across all hours of the year. For the same $\mathrm{CO}_{2}$ emissions intensity limit, this demand flexibility leads to a greater share of VRE generation (see Figure S 3) but less curtailment and increased energy storage capacity compared to the equivalent case without hydrogen (base + RFB scenario). The impact is greatest when non-power sources of $\mathrm{H}_{2}$ supply to meet $\mathrm{H}_{2}$ demand outside the power sector are quite expensive $(\$ 10 / \mathrm{kg})$. 

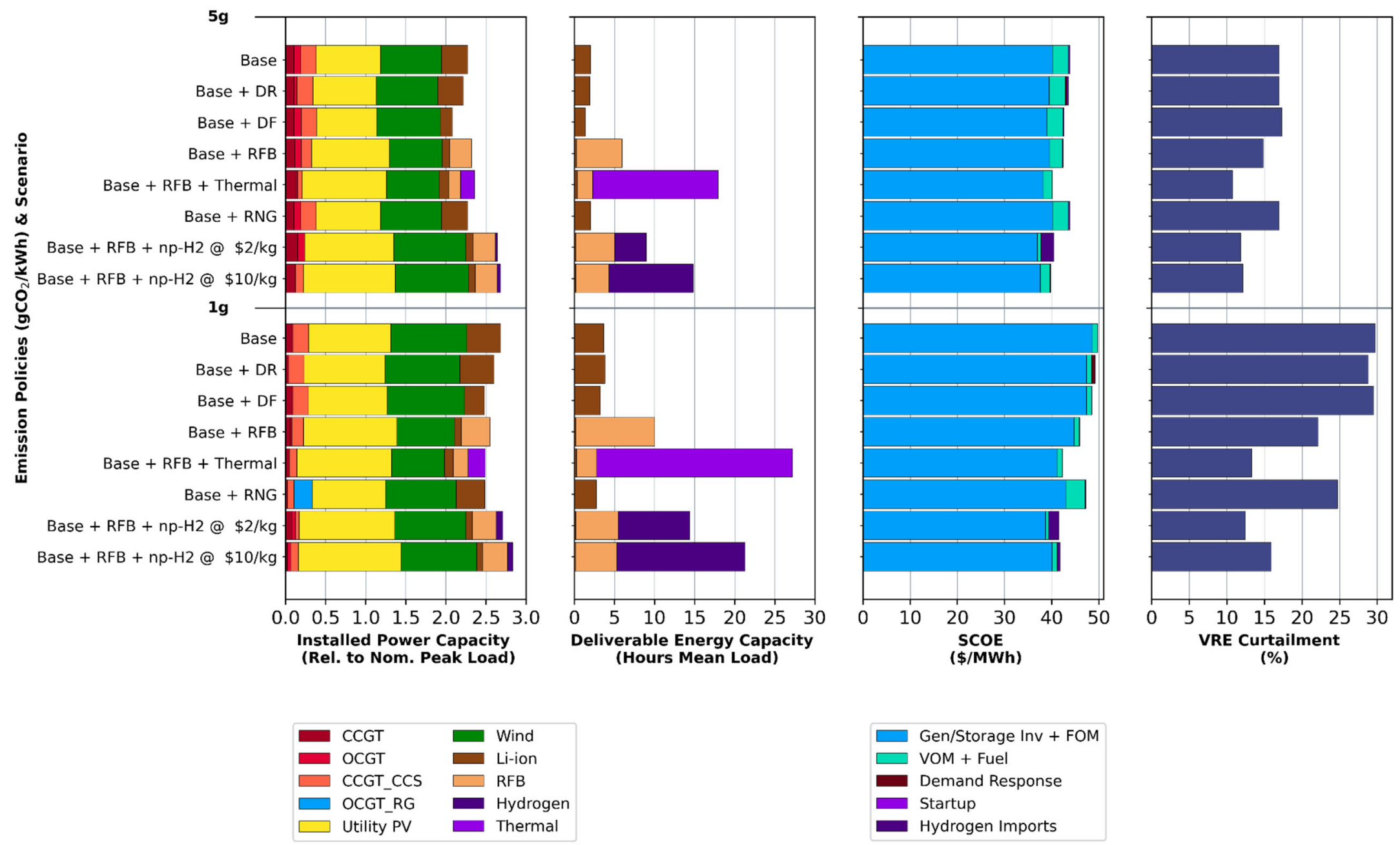

Figure 1.Key system outcomes for various CO2 emissions intensity constraints and technology scenarios. $1^{\text {st }}$ column: installed power capacity by technology type, reported as a fraction of peak load; $2^{\text {nd }}$ column: Deliverable energy storage capacity installed by technology type, reported as a fraction of mean annual demand. Deliverable energy capacity for each storage technology is defined as the installed energy capacity times the discharge efficiency; $3^{\text {rd }}$ column: system average cost of electricity (SCOE), defined as ratio of total system cost by total demand met throughout the year; $4^{\text {th }}$ column: variable renewable energy curtailment, defined as the fraction of available VRE generation that is not dispatched. Note that $R N G$ is not deployed even if made available in the $5 \mathrm{gCO} / \mathrm{kWh}$ and so the results for Base $+\mathrm{RNG}$ are identical to Base Case results. 


\section{Impact on Wholesale Electricity Prices (Marginal value of energy)}

Figure 2 provides information on the impact of alternative assumptions on the frequency distribution of the wholesale electricity price. The bands shown in Figure 2 include the following marginal values: (1) $\$ 0$ to $\$ 5 / \mathrm{MWh}$, characterized mostly by periods of high VRE generation; (2) $\$ 5-\$ 50 / \mathrm{MWh}$ when natural gas is the marginal generator; (3) $\$ 50-\$ 200 / \mathrm{MWh}$ when natural gas capacity needs to be started up and associated start-up costs must be recovered; and (4) $>\$ 200 / \mathrm{MWh}$, which corresponds to scarcity events, including times when storage supplies energy and load-shedding events, if any, are observed. Note that under a $\mathrm{CO}_{2}$ emissions constraint, the shadow price of carbon emissions is reflected in the wholesale price when natural gas generators are on the margin [10]. Under stringent $\mathrm{CO}_{2}$ emissions constraints, natural gas marginal costs, therefore, could be much higher than $\$ 50 / \mathrm{MWh}$ and might be responsible for high prices, i.e. $\$ 200 / \mathrm{MWh}$ or greater. Also, because the marginal cost of supply from storage is based on opportunity cost rather than being physically defined by marginal operating costs, it varies from period to period - consequently, storage charging and discharging can and does occur in multiple price bands (see Figure S 4).

Figure 2 compares the simulated price distributions with the actual price distributions in ERCOT in 2018 and 2019. We see that there are many more hours of very low prices, many fewer hours of prices where natural gas generation is on the margin, and more hours of high scarcity prices. Figure 2 shows that as the $\mathrm{CO}_{2}$ constraint tightens, across all scenarios the number of hours with marginal prices below $\$ 5 / \mathrm{MWh}$ increases, and the number of hours in the price band of $\$ 5-$ \$50/MWh decreases. These trends reflect an increase in the share of VRE generation and a decline in natural gas generation. It is worth reiterating that these model findings are based on what is effectively a representation of a pure, energy-only electricity market structure, in which all 
wholesale (and, implicitly, all retail) transactions occur at the spot market price of electricity. Incorporating other resource adequacy mechanisms, such as capacity markets with a required capacity reserve margin, is likely to reduce the magnitude and frequency of scarcity prices but is unlikely to impact the frequency of low prices [20].
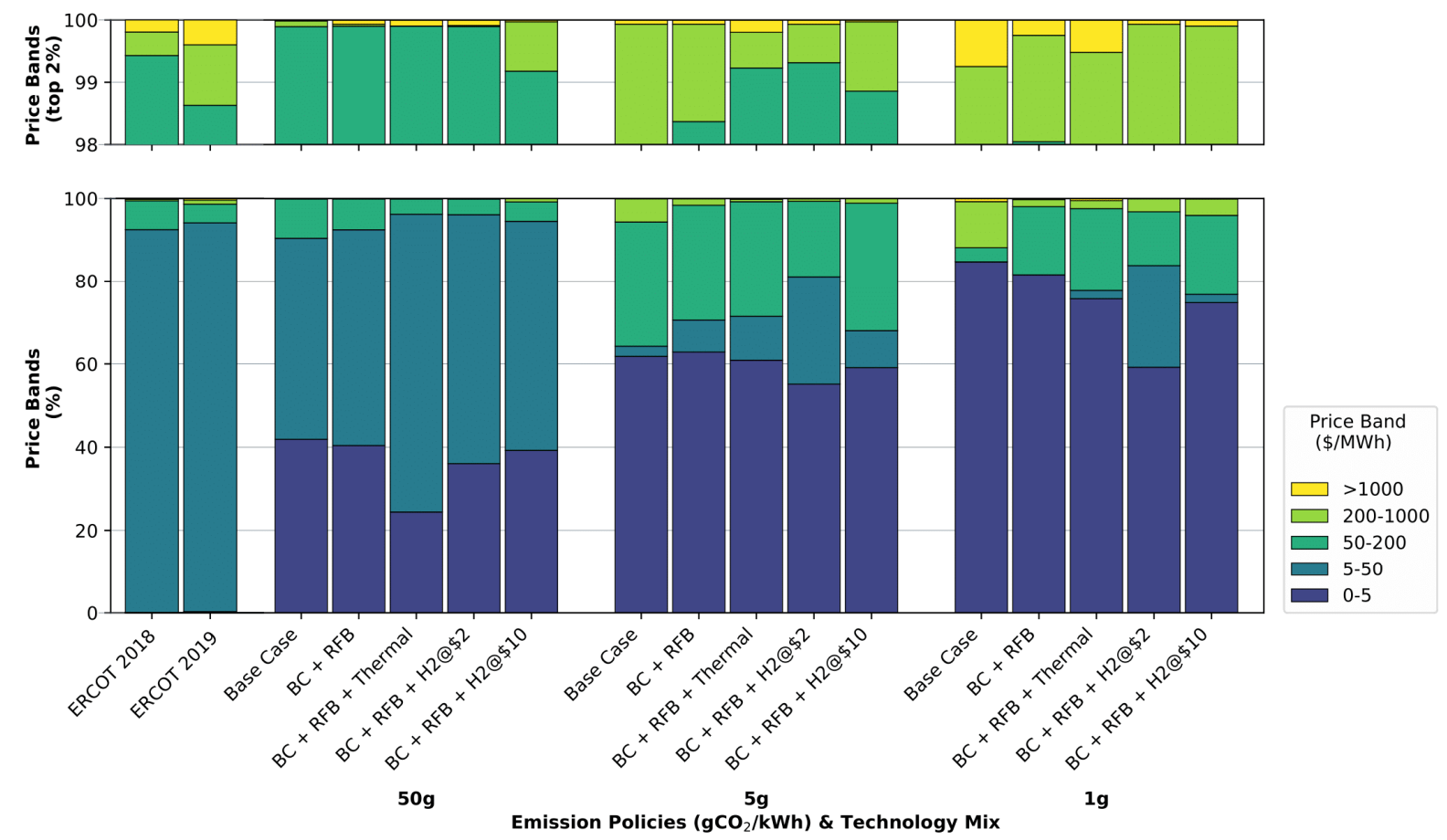

Figure 2. Impact of storage technology, external $\mathrm{H}_{2}$ demand as well as the price of non-power H2 supply on the distribution of electricity prices for various CO2 emissions constraints For comparison, wholesale energy price distributions from ERCOT in 2018 and 2019 are also shown[30]. Technology scenarios evaluated here are described in Table 1. Base case corresponds to Liion as the sole energy storage technology and no external H2 demand. BC =Base Case. RFB = Redox Flow Battery.

A more granular view of the implied wholesale price distributions can be gained from the price duration curves in Figure 3, in which the scenario-specific curves indicate the percentages of hours for which prices are above the corresponding y-axis values. This view makes it easier to see the impacts of technology interventions on the demand side (demand response (DR) and demand flexibility (DF)) as well as of availability of dispatchable, low-carbon fuel (renewable natural gas (RNG)) than the format of Figure 2. Figure 3, again shows that the frequency of low prices increases as the $\mathrm{CO}_{2}$ emissions limit is tightened (left vs. right column). For example, in the base 
case, non-zero prices are observed for approximately $15 \%$ of hours in the $1 \mathrm{gCO}_{2} / \mathrm{kWh}$ as compared to nearly $40 \%$ in the $5 \mathrm{gCO}_{2} / \mathrm{kWh}$ emissions scenario. In the $1 \mathrm{gCO}_{2} / \mathrm{kWh}$, we also see that the adoption of dispatchable low-carbon generation (RNG) reduces instances of near-zero prices that correspond to periods of VRE curtailment (nearly $75 \%$ as compared to $85 \%$ in the base case) and increases instances of prices covering the marginal cost of various dispatchable generation resources, including RNG (\$50-\$330/MWh; see note S1.4). The impact of demand response and demand flexibility is seen in the very high price portion of the curve (see insets in bottom row of Figure 3) where the magnitude and number of instances of high, scarcity prices are reduced compared to the base case. The availability of LDES (RFB, Thermal) compared to the base case, leads to reductions in instances of near-zero prices (due to reduced lower VRE capacity and thus lower VRE curtailment) as well as an increase in the frequency of non-zero prices (e.g. $<\$ 100 / \mathrm{MWh}$ ), when storage charging is effectively setting the wholesale price based on its shadow value of energy. However, the availability of LDES alone does not alter the broader trend of increasing hours with near-zero marginal value of energy and increasing peak prices under tightening $\mathrm{CO}_{2}$ constraints. 

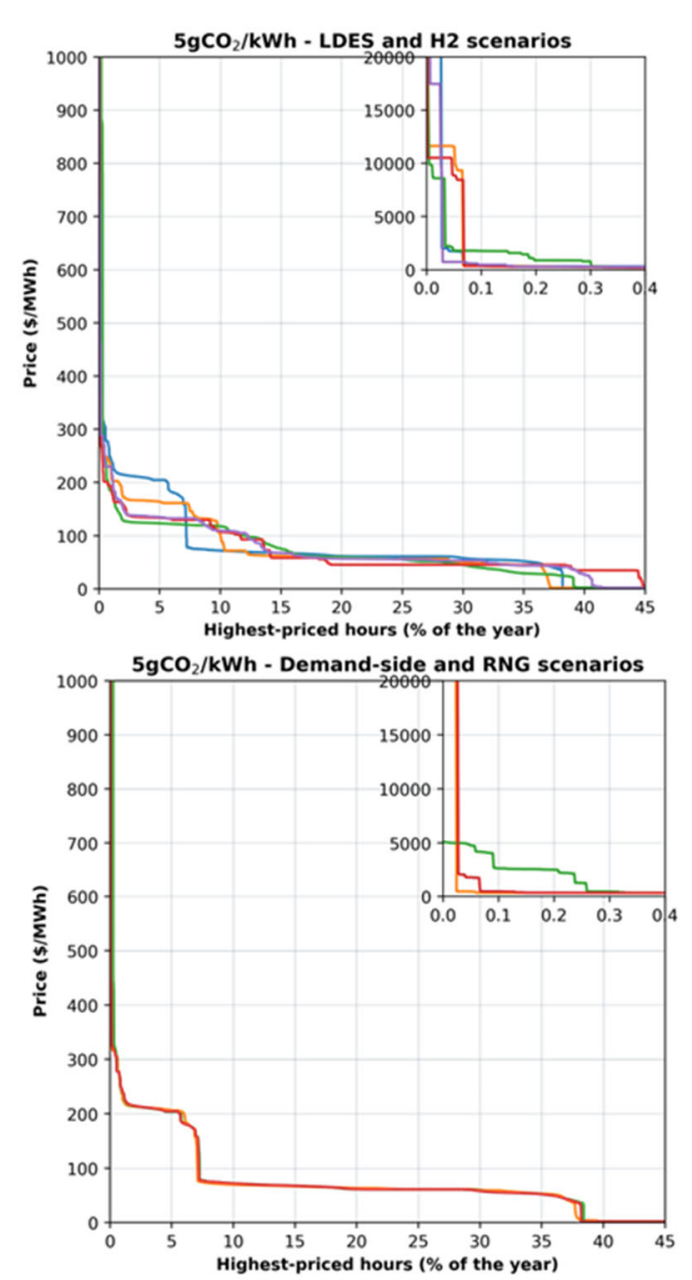
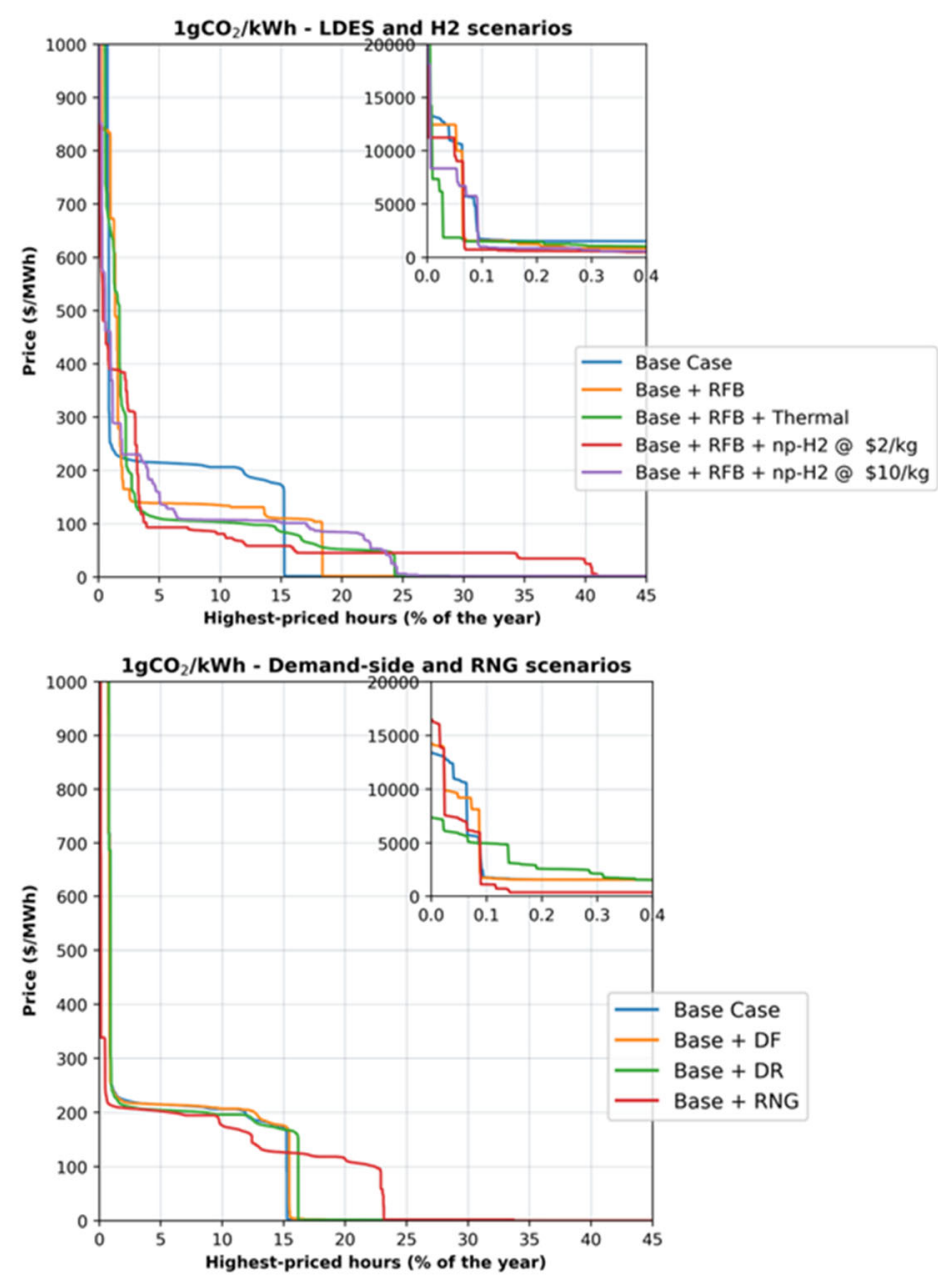

Figure 3. Duration curves for $45 \%$ of the highest marginal electricity price distributions for various technology scenarios and CO2 emissions constraints. Main plot focuses on the $45 \%$ of the hours with prices below $\$ 1000 / M W h$. Inset zooms on the small number of hours $(<0.5 \%$ of hours) when prices are approaching the value of lost load $(\$ 50,000 / \mathrm{MWh})$. The X-axis of the main plot is only shown for $45 \%$ of the total hours to make it easier to see the impacts of various technology availability assumptions and $\mathrm{CO}_{2}$ emissions constraints on the frequency of high prices. In all cases, prices are near zero for the hours that are not shown.

The effect of producing $\mathrm{H}_{2}$ for non-power end-uses on the price distribution is dependent on the cost of non-power $\mathrm{H}_{2}$ supply. When non-power $\mathrm{H}_{2}$ supply is cheap, say $\$ 2 / \mathrm{kg}$, then the opportunity cost of $\mathrm{H}_{2}$ production sets the marginal electricity price for several hours of the year (see red line in top left panel of Figure 3). Specifically, $\$ 2 / \mathrm{kg}$ is equivalent to $\$ 59 / \mathrm{MWh}$ of $\mathrm{H}_{2}$ based on a lower heating value of $\mathrm{H}_{2}$ of $120.1 \mathrm{MJ} / \mathrm{kg}$. When accounting for the electrolyzer efficiency of $77 \%$ (see Table S 2), this translates into a marginal electricity price of $\$ 78 / \mathrm{MWh}$. On the other hand, when non-power $\mathrm{H}_{2}$ supply is expensive, say $\$ 10 / \mathrm{kg}$ in Figure 3, then the 
model places more emphasis on electricity-based hydrogen production, leading to increased VRE deployment and increased frequency of low wholesale electricity prices.

\section{$\underline{\text { Impact of revenues for various resources }}$}

Under the CEM modeling used here, which involves least-cost linear optimization with perfect foresight and constant returns to scale, all resources just break even, meaning that annual revenues over the modeled period equal annualized investment and operational costs $[10,19]$. However, different technologies vary in the fractions of their revenues earned from operation in each price band (Figure 4). With more stringent $\mathrm{CO}_{2}$ constraints, VRE technologies operate more at lower prices but generally rely on a relatively few hours of high prices to earn the revenue required to break even. For example, Figure 2 shows that prices exceed $\$ 200 / \mathrm{MWh}$ for just over $5 \%$ of hours each year, on average, in the Base Case with a $5 \mathrm{gCO}_{2} / \mathrm{kWh}$ constraint, while Figure 4 reveals that PV earns about $30 \%$ of its revenues in those few hours, and Wind and Li-ion earn about $38 \%$ and $60 \%$, respectively. In this scenario with a tight emissions constraint, CCGT and OCGT are essentially only run when the price exceeds \$200/MWh, while CCGT_CCS earns about $42 \%$ of its revenue in those same hours. In short, all resources would be dependent for at least an important fraction of the revenues they need to break even, and in some cases essentially all of those revenues, on sales in a handful of hours under an energy-only wholesale power market design. This conclusion is robust to various technology scenarios considered here (see for example Figure S 5 - Figure S 7). Moreover, optimization ensures full cost recovery in the model because the model assumes perfect foresight of load and VRE availability. In reality, it could be difficult to finance investments in generation and storage assets that have to rely for most of their revenues on a handful of operating hours in any given year. 

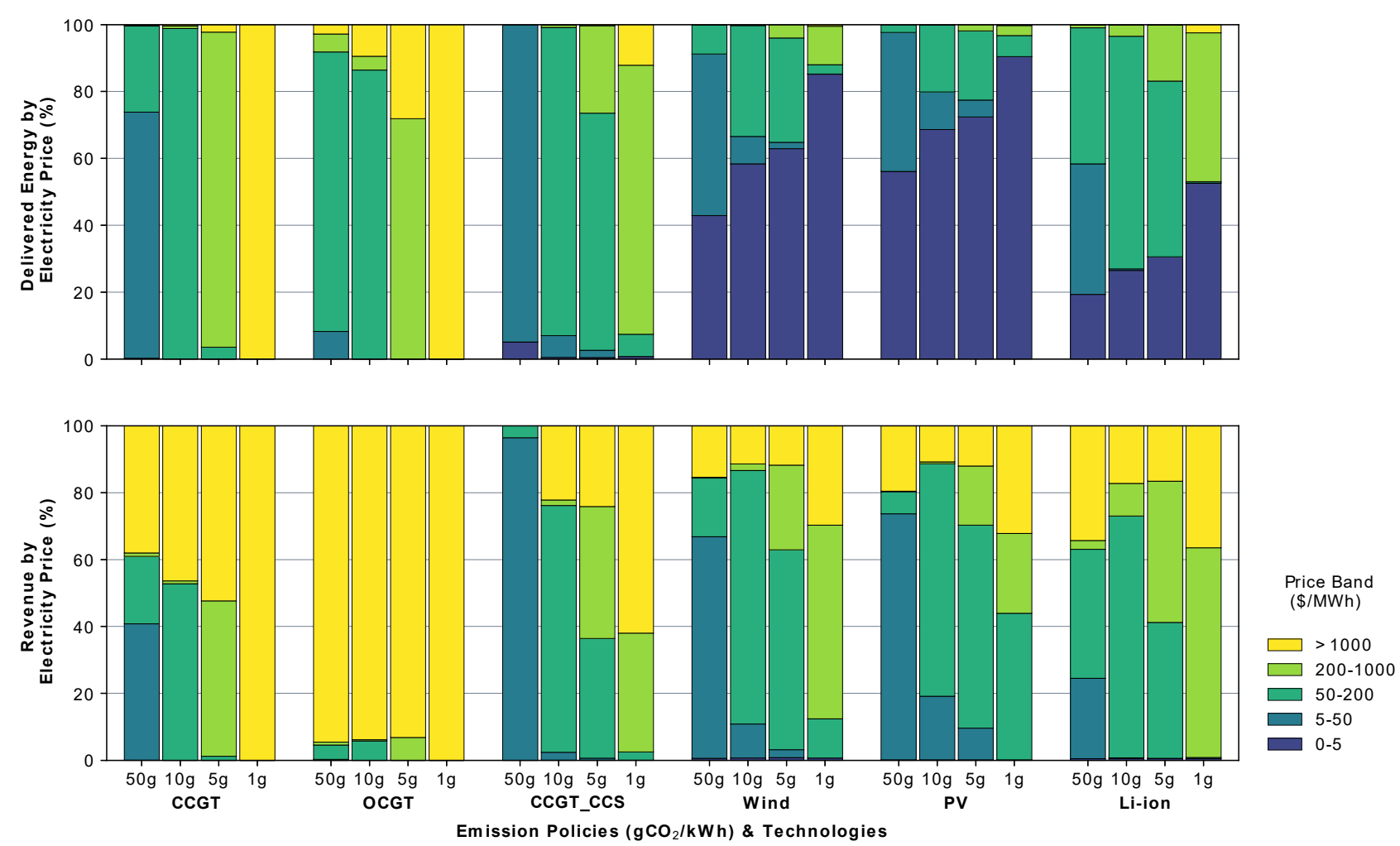

Figure 4. Technology operation and revenue by price band for various resources under the Base Case. The upper panel shows the distribution of delivered energy by price band for different technologies and emission constraints. The lower panel shows the revenue distribution by price band.

\section{Summary and Policy Implications}

As noted above, in many respects our model might be considered a stylized version of the energy-only electricity market operated by ERCOT in Texas. With constraints on carbon emissions, however, our model systems differ from today's ERCOT in important ways that highlight challenges that will face regulators and market designers in all future decarbonized systems. When carbon emissions constraints are tightened, increased reliance on VRE generation becomes optimal, and the proportion of the time when VRE generation is on the margin increases significantly. Since VRE generation has zero or near zero marginal cost, tightening carbon emissions constraints thus increases the incidence of very low prices. High prices are also more common than at present and are necessary cover the system's higher overall cost. This dramatic change in the probability distribution of wholesale prices means that in an 
energy-only market without price caps, generation and storage investments depend for cost recovery on energy market revenues from significantly fewer hours a year than at present. Finally, end consumers in our model systems pay spot wholesale prices for electricity; these prices are much, much more variable than those any real customers now face. It is hard to imagine policy makers allowing these outcomes of our modeled systems to emerge in real systems as decarbonization proceeds. How they respond to those challenges will determine the costs of economy-wide decarbonization and perhaps even its feasibility.

Most organized power markets already have caps on wholesale prices that are below reasonable estimates of the value of lost load, and such caps will almost certainly be present in decarbonizing systems with higher underlying price variability. Such caps reduce energy-market revenues and create the so-called "missing money problem" of sub-optimal incentives for investment in generation [31]. By reducing price variability, such caps will reduce energy arbitrage opportunities for storage facilities and, thus, also reduce incentives to invest in storage below efficient levels. Market designers have responded to the "missing money problem" by introducing a variety of supplemental capacity remuneration mechanisms [32], and these will be even more important in decarbonizing systems. These mechanisms were originally designed for systems dominated by dispatchable thermal generators, however, which have relatively predictable maximum outputs and marginal costs. These capacity remuneration mechanisms need fundamental modification to handle VRE generation, the outputs of which depend on the weather, which also affects demand. Storage facilities, which at any time can only supply the energy they have previously stored, pose more fundamental challenges to the design of capacity mechanisms. 
Unlike the retail customers in our modeled systems, only a few customers (almost exclusively large commercial and industrial concerns) pay wholesale spot prices today. As those prices become more variable, it is hard to imagine regulators requiring more customers to pay them. (The February, 2021 energy crisis in Texas, when a few retail customers who had signed up to pay wholesale spot prices received astronomical bills, has provided a strong push in the opposite direction [33].) To encourage economy-wide decarbonization, however, it is essential that all consumers face low prices when wholesale spot prices - and thus the marginal social cost of electricity - are low. This requires that the costs of supplemental capacity remuneration mechanisms not be recovered by volumetric (per-kwh) charges as at present. These costs should be covered by customer-specific charges that are fixed in the short run but respond to long-run demand patterns and that vary among customers in a politically acceptable way.

At the other end of the price distribution, efficiency requires that the demand for electricity be reduced when its wholesale price is high, most plausibly by shifting demand to other periods. Efficiency does not require that households and small businesses actually pay high wholesale prices, however. We think the most viable solution is for local distribution companies or other intermediaries to contract with small customers to supply electricity at relatively predictable prices in exchange for automated, price-responsive control of vehicle charging, HVAC systems, appliances, and other flexible loads. 


\section{References}

[1] Williams JH, Jones RA, Haley B, Kwok G, Hargreaves J, Farbes J, et al. Carbon-Neutral Pathways for the United States. AGU Adv 2021;2:e2020AV000284. doi:10.1029/2020av000284.

[2] International Energy Agency. Net Zero by 2050: A Roadmap for the Global Energy Sector. Paris, France: 2021.

[3] IPCC. Global Warming of $1.5^{\circ} \mathrm{C}$. An IPCC Special Report on the impacts of global warming of $1.5^{\circ} \mathrm{C}$ above pre-industrial levels and related global greenhouse gas emission pathways, in the context of strengthening the global response to the threat of climate change,. 2018.

[4] Brown PR, Botterud A. The Value of Inter-Regional Coordination and Transmission in Decarbonizing the US Electricity System. Joule 2020. doi:10.1016/j.joule.2020.11.013.

[5] Härtel P, Korpås M. Demystifying market clearing and price setting effects in low-carbon energy systems. Energy Econ 2021;93:105051. doi:10.1016/j.eneco.2020.105051.

[6] Heuberger CF, Staffell I, Shah N, Dowell N Mac. A systems approach to quantifying the value of power generation and energy storage technologies in future electricity networks. Comput Chem Eng 2017;107:247-56. doi:10.1016/J.COMPCHEMENG.2017.05.012.

[7] Sepulveda NA, Jenkins JD, de Sisternes FJ, Lester RK. The Role of Firm Low-Carbon Electricity Resources in Deep Decarbonization of Power Generation. Joule 2018;2:240320. doi:10.1016/J.JOULE.2018.08.006.

[8] Cole WJ, Greer D, Denholm P, Frazier AW, Machen S, Mai T, et al. Quantifying the challenge of reaching a $100 \%$ renewable energy power system for the United States. Joule 2021;5:1732-48. doi:10.1016/J.JOULE.2021.05.011. 
[9] Frew BA, Becker S, Dvorak MJ, Andresen GB, Jacobson MZ. Flexibility mechanisms and pathways to a highly renewable US electricity future. Energy 2016;101:65-78. doi:10.1016/J.ENERGY.2016.01.079.

[10] Brown T, Reichenberg L. Decreasing market value of variable renewables can be avoided by policy action. Energy Econ 2021;100:105354. doi:10.1016/J.ENECO.2021.105354.

[11] Mileva A, Johnston J, Nelson JH, Kammen DM. Power system balancing for deep decarbonization of the electricity sector. Appl Energy 2016;162:1001-9. doi:10.1016/J.APENERGY.2015.10.180.

[12] Johnston J, Henriquez-Auba R, Maluenda B, Fripp M. Switch 2.0: A modern platform for planning high-renewable power systems. SoftwareX 2019;10:100251. doi:10.1016/j.softx.2019.100251.

[13] Brown T, Schlachtberger D, Kies A, Schramm S, Greiner M. Synergies of sector coupling and transmission reinforcement in a cost-optimised, highly renewable European energy system. Energy 2018;160:720-39. doi:10.1016/j.energy.2018.06.222.

[14] Pfenninger S, Pickering B. Calliope: a multi-scale energy systems modelling framework. J Open Source Softw 2018;3:825. doi:10.21105/joss.00825.

[15] Zerrahn A, Schill W-P. Long-run power storage requirements for high shares of renewables: review and a new model. Renew Sustain Energy Rev 2017;79:1518-34. doi:10.1016/J.RSER.2016.11.098.

[16] MIT Energy Initiative and Princeton University ZERO lab. GenX: a configurable power system capacity expansion model for studying low-carbon energy futures n.d. https://github.com/GenXProject/GenX (accessed September 1, 2021).

[17] Biggar DR, Hesamzadeh MR. The Economics of Electricity Markets. Econ Electr Mark 
2014;9781118775752:1-409. doi:10.1002/9781118775745.

[18] Heuberger CF, Bains PK, Mac Dowell N. The EV-olution of the power system: A spatiotemporal optimisation model to investigate the impact of electric vehicle deployment. Appl Energy 2020;257:113715. doi:10.1016/j.apenergy.2019.113715.

[19] Junge C, Mallapragada, Dharik S, Schmalensee R. Energy Storage Investment and Operation in Efficient Electric Power Systems. Cambridge, MA: MIT CEEPR Working Paper; 2021.

[20] Levin T, Botterud A. Electricity market design for generator revenue sufficiency with increased variable generation. Energy Policy 2015. doi:10.1016/j.enpol.2015.09.012.

[21] Wang S, Zheng N, Bothwell CD, Xu Q, Kasina S, Hobbs BF. Crediting Variable Renewable Energy and Energy Storage in Capacity Markets: Effects of Unit Commitment and Storage Operation. IEEE Trans Power Syst 2021.

doi:10.1109/TPWRS.2021.3094408.

[22] Djørup S, Thellufsen JZ, Sorknæs P. The electricity market in a renewable energy system. Energy 2018;162:148-57. doi:10.1016/J.ENERGY.2018.07.100.

[23] Collins S, Deane JP, Poncelet K, Panos E, Pietzcker RC, Delarue E, et al. Integrating short term variations of the power system into integrated energy system models: A methodological review. Renew Sustain Energy Rev 2017;76:839-56. doi:10.1016/J.RSER.2017.03.090.

[24] Mallapragada DS, Papageorgiou DJ, Venkatesh A, Lara CL, Grossmann IE. Impact of model resolution on scenario outcomes for electricity sector system expansion. Energy 2018;163:1231-44. doi:10.1016/j.energy.2018.08.015.

[25] Bernath C, Deac G, Sensfuß F. Impact of sector coupling on the market value of 
renewable energies - A model-based scenario analysis. Appl Energy 2021;281. doi:10.1016/J.APENERGY.2020.115985.

[26] Böttger D, Härtel P. On Wholesale Electricity Prices and Market Values in a CarbonNeutral Energy System 2021.

[27] He G, Mallapragada DS, Bose A, Heuberger CF, Gençer E. Sector coupling via hydrogen to lower the cost of energy system decarbonization 2021.

[28] Mai T, Jadun P, Logan J, Mcmillan C, Muratori M, Steinberg D, et al. Electrification Futures Study: Scenarios of Electric Technology Adoption and Power Consumption for the United States. Golden, CO: 2018.

[29] National Renewable Energy Laboratory (NREL). Annual Technology Baseline 2020. https://atb-archive.nrel.gov/electricity/2020/data.php (accessed September 28, 2021).

[30] Electric Reliability Council of Texas. Historical DAM Load Zone and Hub Prices n.d. http://mis.ercot.com/misapp/GetReports.do?reportTypeId=13060\&reportTitle=Historical DAM Load Zone and Hub Prices\&showHTMLView=\&mimicKey (accessed September $30,2021)$.

[31] Joskow PL. Capacity payments in imperfect electricity markets: Need and design. Util Policy 2008;16:159-70. doi:10.1016/J.JUP.2007.10.003.

[32] Sun Y, Levin T, Kwon J, Xu Q, Singhal N, Ela E, et al. Research Priorities and Opportunities in United States Competitive Wholesale Electricity Markets. Washington, DC: 2021.

[33] Blumscak S. What's behind $\$ 15,000$ electricity bills in Texas? Conversat 2021. https://theconversation.com/whats-behind-15-000-electricity-bills-in-texas-155822 (accessed October 24, 2021). 
[34] Hogan WW, Pope S. Priorities for the Evolution of an Energy-Only Electricity Market Design in ERCOT. Cambridge, MA: 2017.

[35] MIT Energy Initiative. The Future of Energy Storage 2021. https://energy.mit.edu/research/future-of-energy-storage/ (accessed October 10, 2021).

[36] U.S. Energy Information Administration. Annual Energy Outlook 2018: with projections to 2050 . Washington, DC: 2018.

[37] General Electric Power. 7HA Power Plants 2017. https:/www.ge.com/content/dam/gepower-pgdp/global/en_US/documents/product/gas turbines/Fact Sheet/2017-prod-specs/7ha-power-plants.pdf (accessed September 29, 2021).

[38] Kumar N, Besuner P, Lefton S, Agan D, Hilleman D. Power Plant Cycling Costs. Golden, CO: 2012 .

[39] Mallapragada DS, Sepulveda NA, Jenkins JD. Long-run system value of battery energy storage in future grids with increasing wind and solar generation. Appl Energy 2020;275:115390. doi:10.1016/j.apenergy.2020.115390.

[40] National Renewable Energy Laboratory (NREL). National Solar Radiation Database (NSRDB) 2019. https://nsrdb.nrel.gov/ (accessed March 19, 2019).

[41] Sandia National Laboratories. PV Performance Modeling Collaborative 2018.

[42] National Renewable Energy Laboratory (NREL). Wind Integration National Dataset Toolkit n.d. https://www.nrel.gov/grid/wind-toolkit.html (accessed August 10, 2019).

[43] Wind-turbine-models.com. Gamesa G126-2.5MW n.d. https://en.wind-turbinemodels.com/turbines/1286-gamesa-g126-2.5mw (accessed September 29, 2021).

[44] Federal Energy Regulatory Commission. Assessment of Demand Response \& Advanced 
Metering. Washington, DC: 2016.

[45] International Energy Agency. The Future of Hydrogen: Seizing today's opportunities. Paris, France: 2019.

[46] Sunny N, Dowell N Mac, Shah N. What is needed to deliver carbon-neutral heat using hydrogen and CCS? Energy Environ Sci 2020;13:4204-24. doi:10.1039/D0EE02016H.

[47] Mcmillan C. 2018 Industrial Energy Data Book 2019. https://data.nrel.gov/submissions/122 (accessed September 29, 2021).

[48] Liu Y, McMillan C. 2018 Industrial Energy Data Book. Golden, CO: 2019. 


\section{Appendix}

\section{$\underline{\text { S1. Background notes on systems modeling }}$}

1. The modeled marginal value of energy or wholesale electricity price in each time period represents the increase in (minimized) objective function value required to serve the next unit of demand. Because the model includes the option of adding new capacity, generation, storage or transmission, the computed marginal value of energy represents the long-run marginal value of electricity rather than the short-run value in which capacity decisions are fixed. Of course, when VRE generation is being curtailed, adding capacity would not relax a (non-binding) constraint. Finally, the wholesale price computed here does not reflect the impact of short- and long-term capacity requirements that are often included in organized markets to ensure resource adequacy.

2. Electricity price outputs are commonly reported by studies simulating grid operations using industry-standard production cost models (PCMs) that closely mimic realistic economic dispatch of the grid over a short-time horizon (typically 24 hours). PCMs are not useful for analyzing electricity prices for deep decarbonization scenarios for two key reasons. First, PCMs don't consider investment costs and so cannot optimize asset portfolios. Second, the prices generated by PCMs do not ensure full cost recovery for all resources, which means the impact of various policies that affect capital cost cannot be compared via these models.

3. Most U.S. wholesale markets have separate energy and capacity prices. The wholesale prices that we simulate here are most comparable to those observed in so-called "energy-only" wholesale markets like ERCOT where a capacity remuneration mechanism (ORDC) includes all energy and capacity payments in the wholesale energy price [34]. 
4. $\mathrm{RNG}$ generation is parameterized with a heat rate of $9.5 \mathrm{MMBtu} / \mathrm{MWh}$, which translates into a variable cost of \$190/MWh for the assumed fuel price of \$20/MMBtu. We also model the cost of starting up an RNG generator with the possibility of fractional startups, given the linear model formulation. The net impact is that the marginal costs of RNG generator can vary between \$190/MWh and near \$330/MWh.

\section{$\underline{\text { S2. Generator and storage cost and performance assumptions }}$}

Fossil-powered generation and VRE capital and operational costs are shown in Table S 1. The gas, VRE, and Li-ion costs are taken from the 2020 NREL Annual Technology Baseline 2045 "Mid" cost projections[29]. Capital costs for generation and storage were annualized based on an after-tax weighted average cost of capital of $4.5 \%$ and a lifetime of 30 years, unless otherwise noted. We also apply a small, non-zero VOM for wind, hydropower, and storage to distinguish their dispatch as part of the economic dispatch modeled within GenX - they do not meaningfully affect resulting system costs.

For storage, system costs are separated as energy-only components (e.g., battery packs for Li-ion, tanks for LDES), or power-only components (e.g., inverter, interconnection and permitting fees, land acquisition costs). In the case of hydrogen and thermal storage, power-only components can further be parsed into charging or discharging power costs (see Table S 2), which are applied to the respective sizing variables in the model. This separation of functionbased costs enables the model to independently vary the energy, discharging power, and charging power capacities of the energy storage systems for optimal sizing. For storage technologies other than Li-ion, cost projections used in the analysis are based on bottom-up analysis by MIT team members engaged in the forthcoming Future of Storage study[35]. 
Operational assumptions for natural gas powered generators are summarized in Table S 3 .

Natural gas fuel price assumptions are taken from the EIA AEO 2020 Reference (EIA 2021)

2050 case and correspond to $\$ 4.16 /$ MMBtu. For CCGT with CCS, the fuel cost is updated to account for assumed $\mathrm{CO} 2$ transport and storage cost of $\$ 20 /$ tonne of capture $\mathrm{CO}_{2}(90 \%$ flue gas $\mathrm{CO} 2$ capture).

\begin{tabular}{|c|c|c|c|}
\hline Technology & $\begin{array}{c}\text { Capital Cost } \\
(\$ / \mathbf{k W})\end{array}$ & $\begin{array}{c}\text { FOM (\$/kW- } \\
\text { year) }\end{array}$ & $\begin{array}{c}\text { vom } \\
\text { (\$/MWh) }\end{array}$ \\
\hline Onshore Wind & 1,085 & 34.6 & 0.01 \\
\hline Utility-Scale Solar & 725 & 8.5 & 0.00 \\
\hline CCGT & 936 & 12.9 & 2.16 \\
\hline OCGT & 854 & 11.4 & 4.50 \\
\hline CCGT_CCS & 2,080 & 27.0 & 5.72 \\
\hline
\end{tabular}

Table S 2.Energy storage cost and operational assumptions. Value for Li-ion storage from NREL annual technology baseline 2020. Values for other technologies based on bottom-up analysis from MIT team members of the upcoming MIT Energy Initiative Future of Storage Study. RFB = Redox Flow Battery. Round-trip efficiency (RTE) expressed as a fraction is the product of Efficiency Up and Efficiency Down similarly expressed. Hourly self-discharge rates for storage technologies are also considered in the modeling, but are very small at: $0.002 \%$ for Li-ion and metal-air systems, and $0.02 \%$ for thermal systems.

\begin{tabular}{|c|c|c|c|c|c|c|c|c|c|}
\hline Tech & $\begin{array}{c}\text { Discharging } \\
\text { Capital Cost } \\
(\$ / \mathbf{k W})\end{array}$ & $\begin{array}{l}\text { Charging } \\
\text { Capital } \\
\text { Cost } \\
(\$ / \mathrm{kW})\end{array}$ & $\begin{array}{c}\text { Storage } \\
\text { Capital } \\
\text { Cost } \\
\text { (\$ } / \mathbf{k W h})\end{array}$ & $\begin{array}{l}\text { FOM } \\
\text { (\$/kW- } \\
\text { year) }\end{array}$ & $\begin{array}{c}\text { FOM } \\
\text { (\$/kWh- } \\
\text { year) }\end{array}$ & $\begin{array}{c}\text { VOM } \\
\text { (\$/kWh) }\end{array}$ & $\begin{array}{c}\text { Efficiency } \\
\text { Up (\%) }\end{array}$ & $\begin{array}{l}\text { Efficiency } \\
\text { Down (\%) }\end{array}$ & RTE (\%) \\
\hline Li-ion & 110 & - & 125.8 & 0.8 & 2.2 & 0.0 & $92 \%$ & $92 \%$ & $85 \%$ \\
\hline RFB & 396 & - & 48.0 & 4.1 & 0.0 & 0.0 & $92 \%$ & $88 \%$ & $80 \%$ \\
\hline Hydrogen & 1,190 & 479.3 & 7.0 & 11.0 & 0.1 & 0.0 & $77 \%$ & $65 \%$ & $50 \%$ \\
\hline Thermal & 736 & 3.3 & 5.4 & 3.9 & 0.0 & 0.0 & $100 \%$ & $50 \%$ & $50 \%$ \\
\hline
\end{tabular}

Table S 3.Thermal generator operational characteristics for the GenX model runs presented in the main text. Data compiled after surveying a variety of literature sources including NREL Annual Technology Baseline[29] EIA Annual Energy Outlook 2018[36], other sources[7,37-39] [13,54,57,59] CCGT = Combined Cycle Gas Turbine. OCGT=Open Cycle Gas Turbine. CCS $=$ CO 2 capture and storage.

$\begin{array}{lcccccc}\text { Tech } & \begin{array}{c}\text { Capacity Size } \\ \text { (MW) }\end{array} & \begin{array}{c}\text { Start } \\ \text { Cost (\$) }\end{array} & \begin{array}{c}\text { Start Cost } \\ \text { (\$⿳/MW/start) }\end{array} & \begin{array}{c}\text { Start Fuel } \\ \text { (MMBTU/ } \\ \text { start) }\end{array} & \begin{array}{c}\text { Start Fuel } \\ \text { (MMBTU/ } \\ \text { MW/start) }\end{array} & \begin{array}{c}\text { Heat Rate } \\ \text { (MMBTU/ } \\ \text { MWh) }\end{array} \\ \text { OCGT } & 237 & 33,147 & 140 & 45 & 0.19 & 9.51 \\ \text { CCGT } & 573 & 34,982 & 61 & 115 & 0.20 & 6.40\end{array}$




\begin{tabular}{lrrrrrr} 
CCGT + CCS & 377 & 36,419 & 97 & 75 & 0.20 & 7.12 \\
\hline Tech & & & & & Min Stable \\
Output (\%) & $\begin{array}{c}\text { Ramp } \\
\text { Up (\%) }\end{array}$ & Ramp Down (\%) & $\begin{array}{c}\text { Up Time } \\
\text { (Hours) }\end{array}$ & $\begin{array}{c}\text { Down Time } \\
\text { (Hours) }\end{array}$ \\
OCGT & 25 & 100 & 100 & 0 & 0 \\
CCGT & 30 & 100 & 100 & 4 & 4 \\
CCGT + CCS & 50 & 100 & 100 & 4 & 4 \\
\hline
\end{tabular}

\section{$\underline{\text { S3. VRE Resource characterization }}$}

VRE resources are characterized based on the methodology described in [4]. Hourly PV capacity factors are simulated using 2007-2013 weather data from the NREL National Solar Radiation Database [40] through the PVLIB model framework[41], at a 4km x 4km spatial resolution. Hourly wind capacity factors are simulated using the same temporal and spatial resolution using the NREL Wind Integration National Dataset Toolkit [42] and power curve data for the commercial wind turbine Gamesa:G126/2500[43] at 100-meter height. To reduce the spatial resolution of the VRE capacity factor data, we aggregate sites within a zone on the basis of average levelized cost of electricity (including the cost of interconnecting to the nearest substation). Thus, for each resource and zone, we get a supply curve, with each bin representing increasing resource quality with an associated maximum availability (based on land area), interconnection cost and hourly capacity factor profile. For the Texas case study, we use 4 bins to characterize PV and wind resources in the region. Note that the interconnection cost of each bin is added on to the base capital cost of the technology, noted in Table S 1, to develop a binspecific installed capital cost.

\section{$\underline{\text { S4. Demand flexibility scenario definition }}$}

The potential value of flexibility in electricity consumption for various end-uses increases with greater deployment of smart meters and related technologies and expanded electrification in sectors such as transportation. For these experiments, we consider a very optimistic version of 
demand flexibility: the ability to shift electricity consumption from specific demand subsectors, highlighted in Table S 4, over constrained (feasible) time windows at zero cost and with zero energy efficiency losses or inconvenience costs. Our assumptions about demand flexibility are based on the NREL EFS enhanced flexibility scenario, which provides potential hours of delay and advance for specific demand subsectors, along with the share of the load that can be shifted[28]. Since the load from each subsector changes over time, potential demand flexibility also varies from hour to hour. For this reason, Table S 4 notes the maximum load that could be shifted for each subsector at any point in time for the Texas region in 2050 under the highelectrification load scenario. It is important to notice that these subsector peaks do not occur at the same time; the actual maximum potential demand flexibility at any particular hour is $47 \mathrm{GW}$, which corresponds to $31 \%$ of total demand in that hour [28].

Table S 4. Demand flexibility assumptions for Texas under 2050 load conditions. HVAC = heating, ventilation and air Conditioning. Data sourced from NREL Electrification Futures Study

\begin{tabular}{|c|c|c|c|c|}
\hline Demand Subsector & $\begin{array}{l}\text { Hours } \\
\text { Delay }\end{array}$ & $\begin{array}{c}\text { Hours } \\
\text { Advance }\end{array}$ & $\begin{array}{c}\text { Share of End-Use That Is } \\
\text { Flexible }\end{array}$ & $\begin{array}{l}\text { Maximum Hourly Demand } \\
\text { Flexibility [GW] }\end{array}$ \\
\hline Commercial HVAC & 1 & 1 & $25 \%$ & 8.6 \\
\hline Residential HVAC & 1 & 1 & $35 \%$ & 7 \\
\hline $\begin{array}{l}\text { Commercial Water } \\
\text { Heating }\end{array}$ & 2 & 2 & $25 \%$ & 0.2 \\
\hline $\begin{array}{c}\text { Residential Water } \\
\text { Heating }\end{array}$ & 2 & 2 & $25 \%$ & 1 \\
\hline Light duty vehicles & 5 & 0 & $90 \%$ & 33 \\
\hline Medium duty trucks & 5 & 0 & $90 \%$ & 3 \\
\hline Heavy-duty trucks & 3 & 0 & $90 \%$ & 5 \\
\hline
\end{tabular}

\section{$\underline{\text { S5. Demand response scenario definition }}$}

The demand response scenario modeled here assumes that certain electricity consumers will be willing to forgo consumption above certain electricity prices. These type of demand response programs exist in some regions and are typically used for peak demand management [44]. To capture the underlying goal of these programs for supply-demand balancing, the stylized demand response scenario modeled here assumes that $25 \%$ of hourly load in each can be shed at 
prices below the value of lost load $(\$ 50,000 / \mathrm{MWh})$. Table S 5 summarizes the parametrization of this demand response resource in GenX where demand segments 2-6 have an associated quantity ( $5 \%$ of hourly demand) and marginal cost,that is measured as a fraction of the value of lost load.

Demand segment 1 is the most expensive and is priced at the value of lost load.

Table S 5 Demand response resource characterization. VoLL $=$ Value of Lost Load, set to $\$ 50,000 / M W h$.

\begin{tabular}{|ccc|}
$\begin{array}{c}\text { Demand } \\
\text { segment }\end{array}$ & $\begin{array}{c}\text { Cost of demand curtailment as a fraction } \\
\text { of VoLL }\end{array}$ & $\begin{array}{c}\text { Maximum demand curtailment per segment as a fraction of } \\
\text { hourly load }\end{array}$ \\
\hline $\mathbf{1}$ & 1 & $75 \%$ \\
\hline $\mathbf{2}$ & 0.7 & $5 \%$ \\
\hline $\mathbf{3}$ & 0.5 & $5 \%$ \\
\hline $\mathbf{4}$ & 0.2 & $5 \%$ \\
\hline $\mathbf{5}$ & 0.1 & $5 \%$ \\
\hline $\mathbf{6}$ & 0.05 & $5 \%$ \\
\hline
\end{tabular}

\section{$\underline{\mathrm{S} 6 . \mathrm{H}_{2}}$ scenario definition}

The configuration of Figure S 1 is included in the GenX model, where along with specifying the cost of performance assumptions of the elements as used previously (e.g., electrolyzer, storage tank and gas turbines for $\mathrm{H}_{2}$ storage as per values in Table $\mathrm{S} 2$ ), we add a constraint that requires the specified $\mathrm{H}_{2}$ demand from industry to be met by either the electrolyzer or by discharging $\mathrm{H}_{2}$ storage. This single constraint then enables the utilization of a traditional power-to- $\mathrm{H}_{2}$-to-power storage system to be also optimized, in terms of component sizes and utilization, to meet $\mathrm{H}_{2}$ demand in the industrial sector.

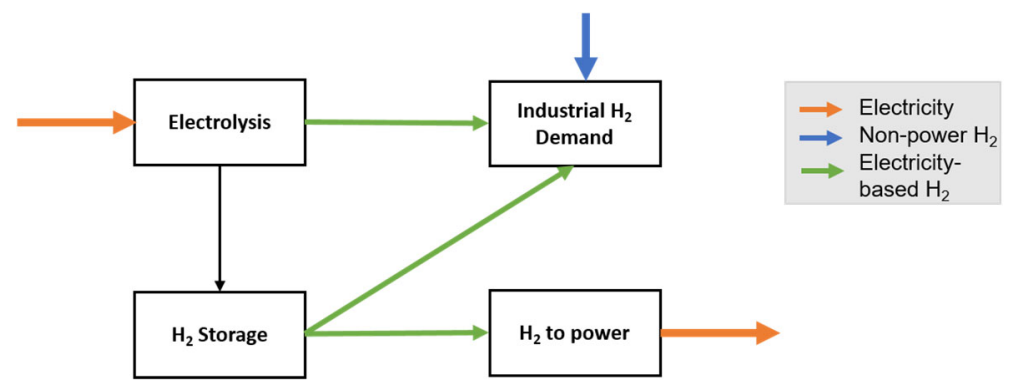

Figure S 1.Representation of the power to $\mathrm{H}_{2}$ to power system within GenX and hydrogen's use for meeting industrial hydrogen demand. 
Since we are primarily interested in understanding the impact on the power system from this external $\mathrm{H}_{2}$ demand, we make the following approximations to simplify the representation of the $\mathrm{H}_{2}$ supply chain. (1) We simplify the representation of non-power sources of $\mathrm{H}_{2}$ supply, by making them available at a constant cost, either $\$ 2 / \mathrm{kg}$ or $\$ 10 / \mathrm{kg}$, without any supply limits. As reference, the cost of producing hydrogen from natural gas with carbon capture and storage is estimated to be around $\$ 2 / \mathrm{kg}$ in the U.S. context[45]. (2) We are not considering any spatial distribution in $\mathrm{H}_{2}$ production and industrial demand and are thus ignoring $\mathrm{H}_{2}$ transportation. And, (3) we are not including source-dependent delivery costs for $\mathrm{H}_{2}$ supply that could be associated with adjusting the state of delivered $\mathrm{H}_{2}$ from different sources to meet industrial customer requirements. Other studies have included these factors in the $\mathrm{H}_{2}$ supply chain while also contemplating their impacts on the power system evolution $[27,46]$.

Hydrogen demand is modeled as exogenous and uniform throughout the year. Hydrogen demand was estimated using NREL's 2018 Industrial Data Book as a reference[47,48]. This publication contains a dataset detailing the annual energy consumed by large energy-using facilities ${ }^{1}$ in 2016 . Here, we focus on hydrogen demand from substituting for the use of natural gas for heating purposes. Total natural gas consumption by Large Energy Users in Texas accounted for 0.93 QBTU in 2016, which represents about 44\% of the 2.1 QBTU of natural gas consumed by the industry in Texas, as reported by the EIA (Figure S 2). From that 0.93 QBTU, we considered for the analysis Process Heaters, Furnaces, Boilers and Other Combustion Sources as potential units that use natural gas for heating purposes. Moreover, we excluded units whose unit name suggests natural gas is being used as feedstock. This results in 0.59QBTU of natural gas used for heating. By assuming flat demand, the total of 0.59QBTU/year of natural gas heat is

\footnotetext{
${ }^{1}$ Defined as those facilities that are required to report greenhouse gas emissions under EPA's Greenhouse Gas Reporting Program.
} 
equivalent to $19.7 \mathrm{GWt}$ of $\mathrm{H}_{2}$. For comparison purposes a constant $19.7 \mathrm{GWt}$ load is equivalent to an average power demand of $25.6 \mathrm{GWe}$ assuming $77 \%$ charging (electrolyzer) efficiency. 25.6

GWe is equal to approximately $17 \%$ of projected 2050 peak electricity demand modeled here.

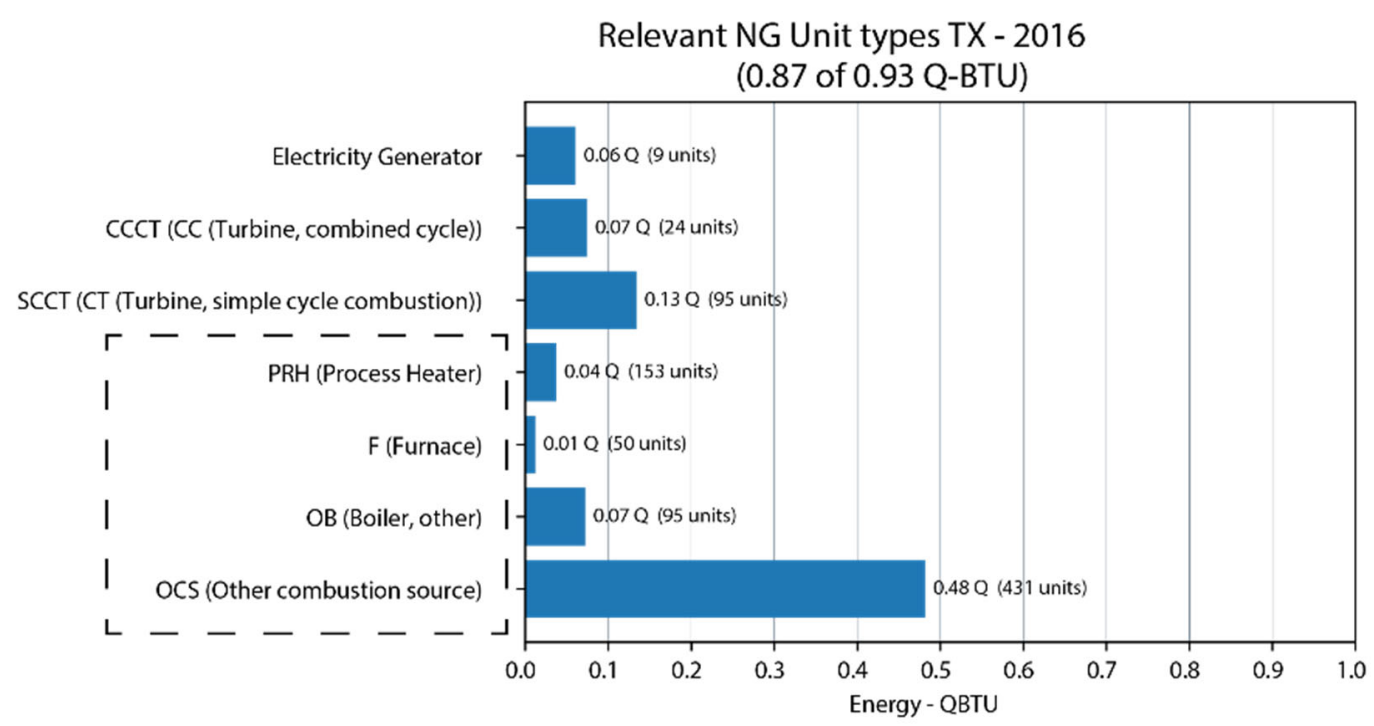

Figure S 2. Natural gas consumption by Large Energy Users in Texas. Demand categories within the dotted box are considered when estimating potential future hydrogen demand for process heating. 


\section{$\underline{\text { S7. Additional Results }}$}

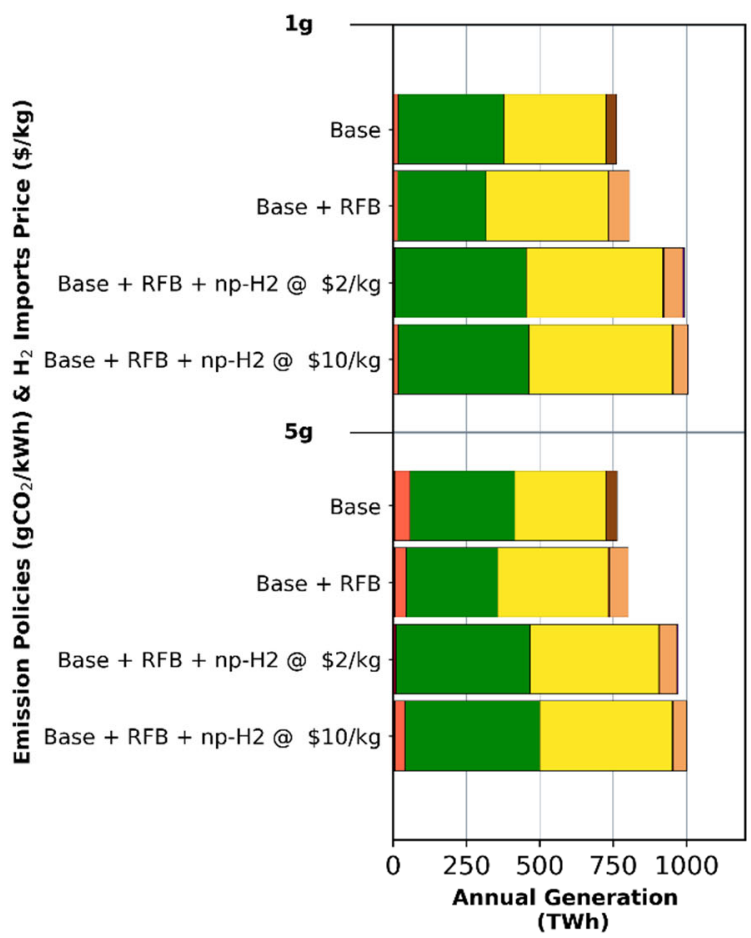

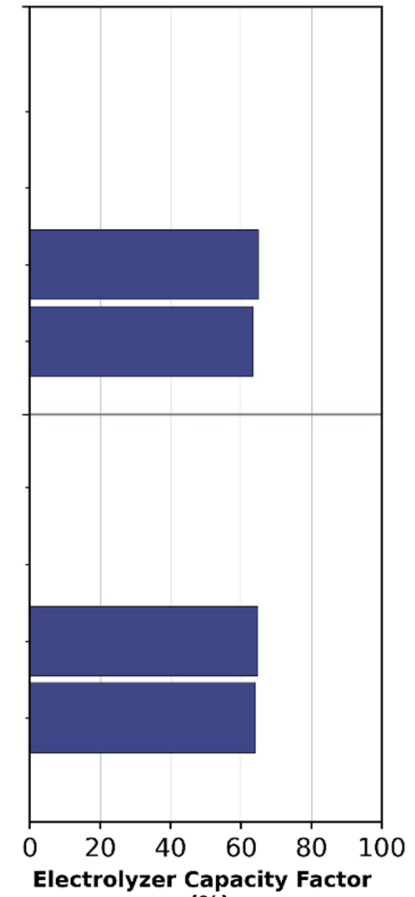

(\%)

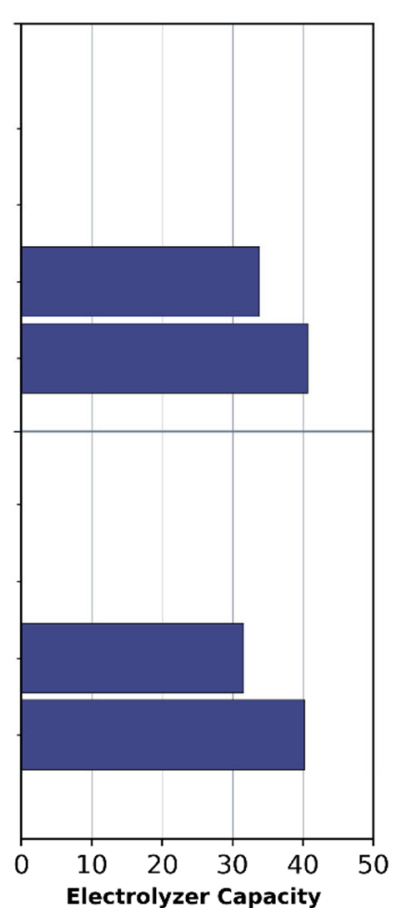

(GW)

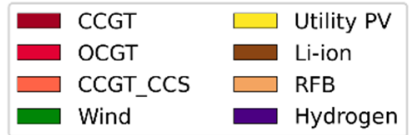

Figure S 3. Key system outcomes for various CO2 emissions intensity constraints and technology scenarios characterized by energy storage availability, existence of non-power $\mathrm{H}_{2}$ demand and availability of non-power $\mathrm{H}_{2}$ supply at various prices. 1 st column: annual generation mix by resource and storage discharging; 2nd column: annual average power to $\mathrm{H}_{2}$ (or electrolyzer) capacity utilization; $3^{\text {rd }}$ column: installed power to hydrogen production capacity. 

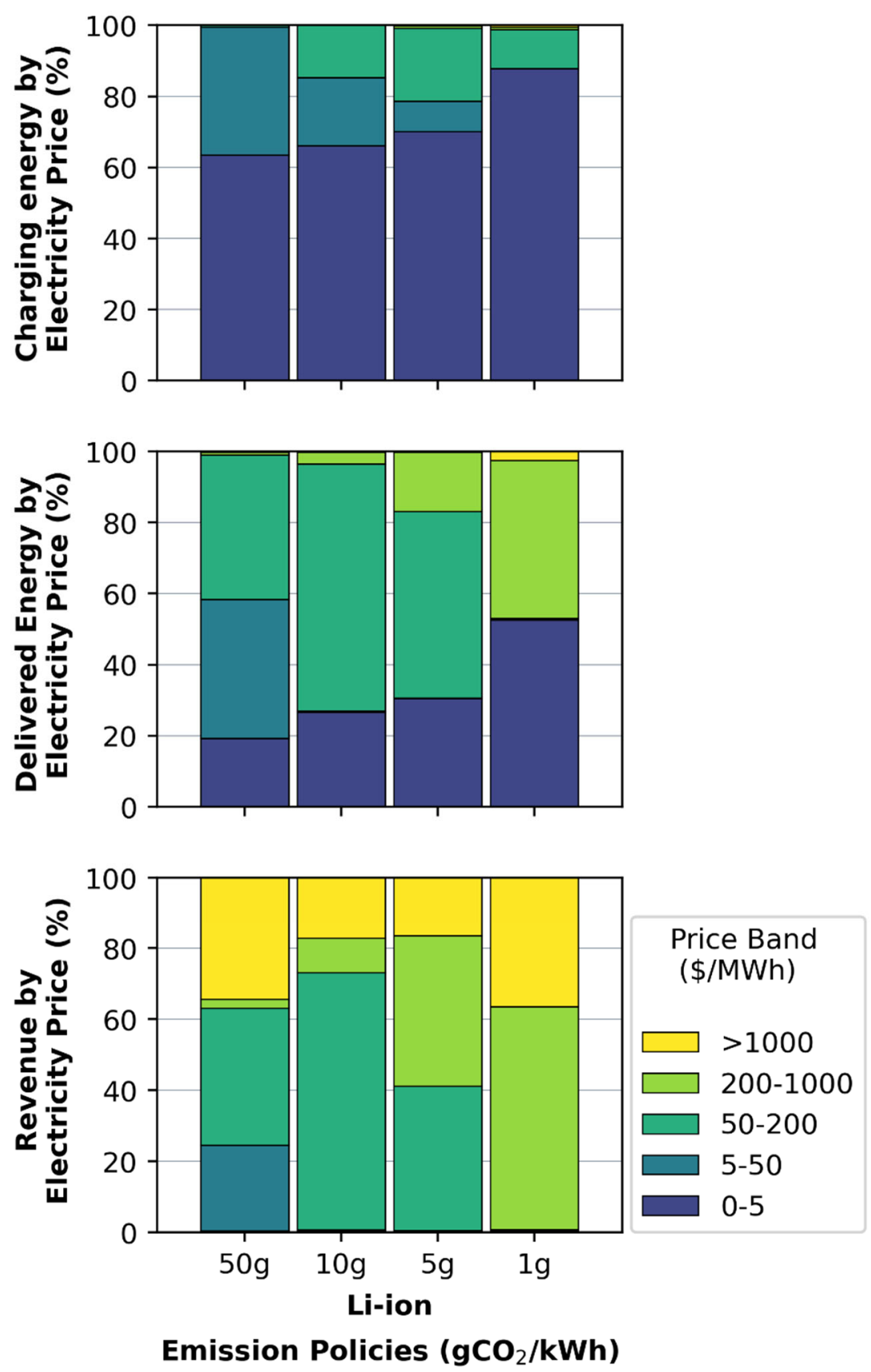

Figure S 4. Distribution of Li-ion storage annual charging (top), discharging energy (middle) and revenue earned (bottom) across the wholesale electricity price bands introduced earlier. Results shown for various CO2 emissions constraints and correspond to "Base" technology scenario described in Table 1. Note that Li-ion charges predominantly, but not exclusively, when prices are in the lowest band. 

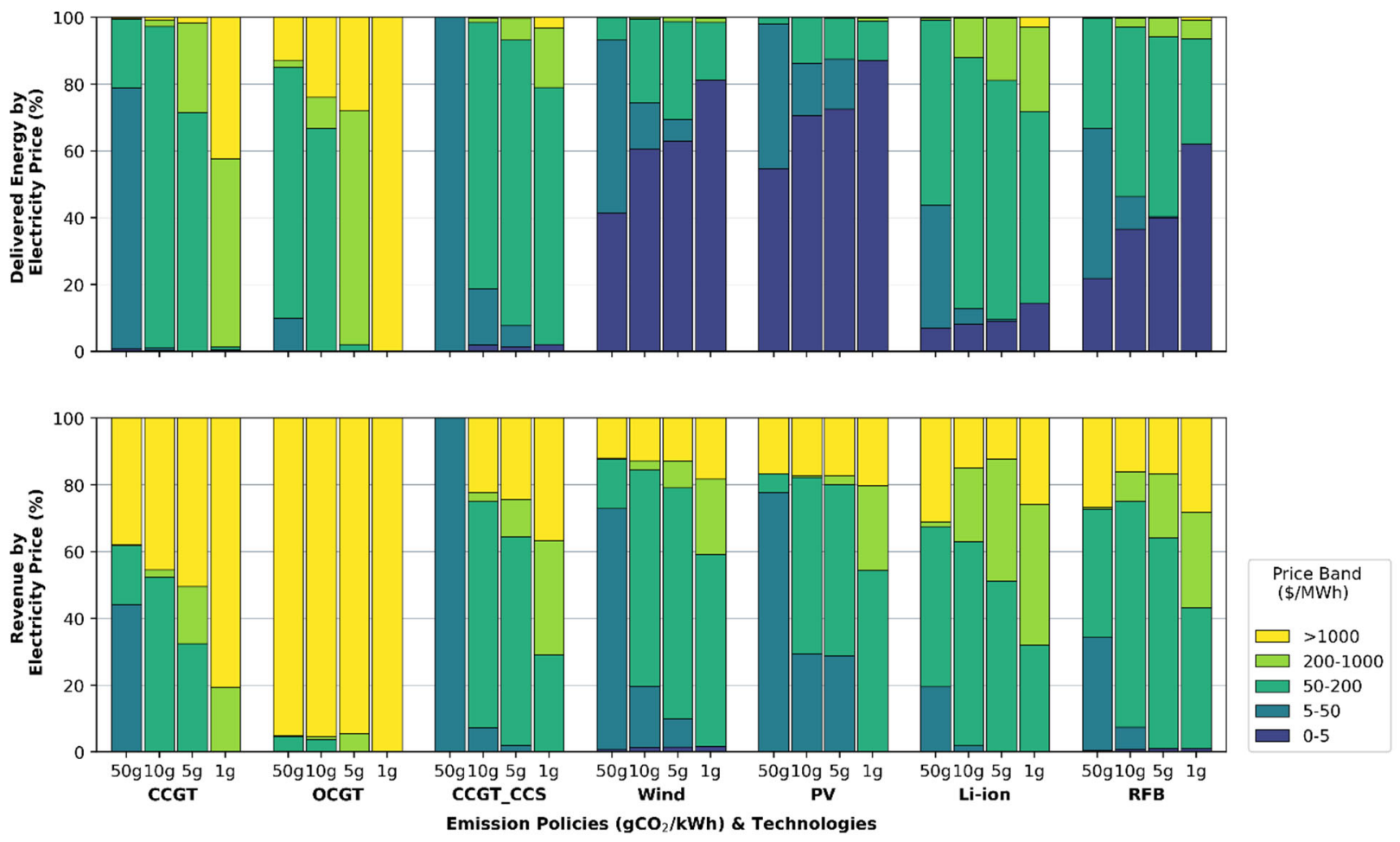

Figure S 5. Technology operation and revenue by price band for various resources under the Base $+R F B$ scenario defined in Table 1. The upper panel shows the distribution of delivered energy by price band for different technologies and emission constraints. The lower panel shows the revenue distribution by price band.
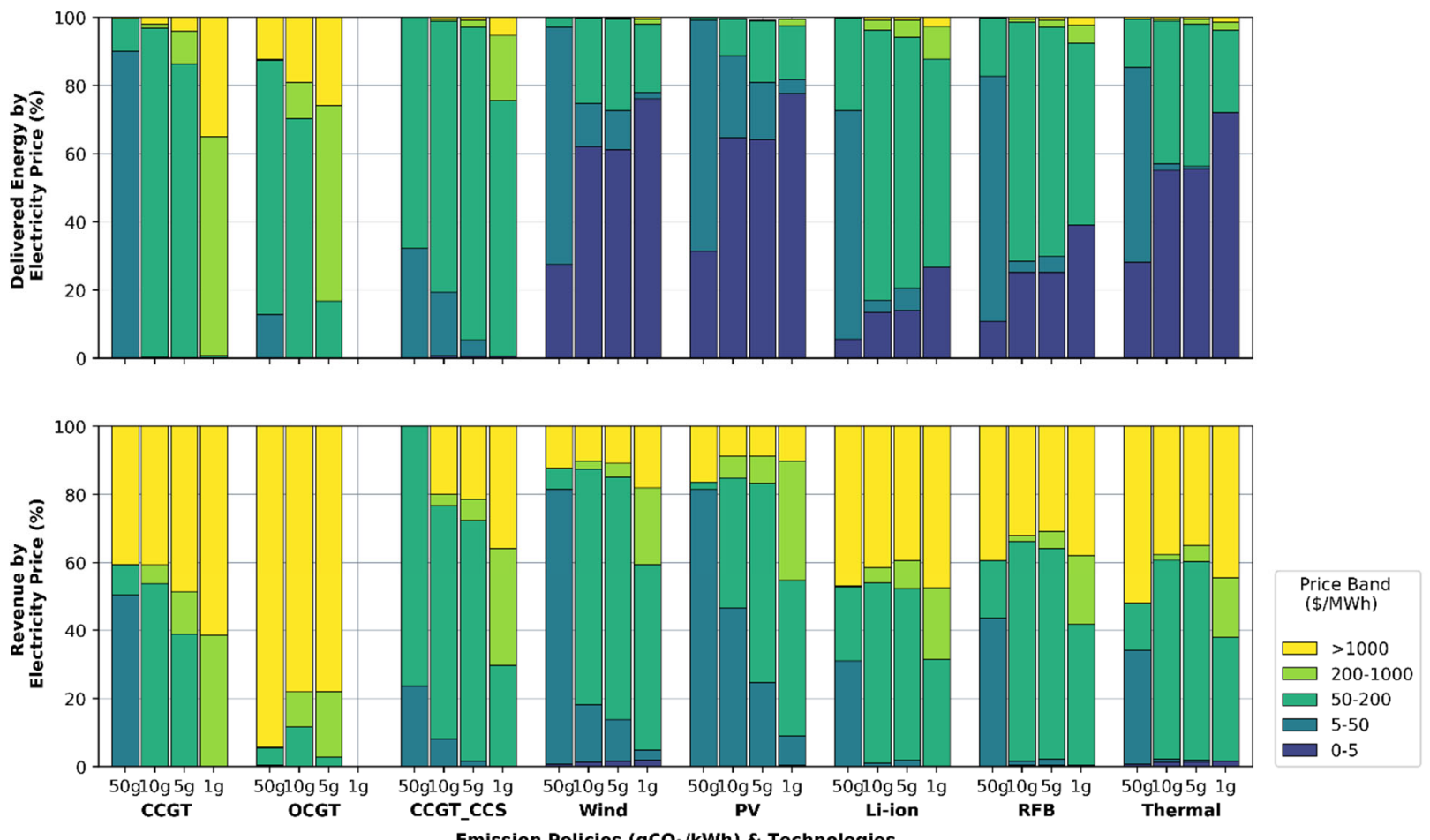

Figure S 6. Technology operation and revenue by price band for various resources under the Base $+R F B+$ Thermal scenario defined in Table 1. The upper panel shows the distribution of delivered energy by price band for different technologies and emission constraints. The lower panel shows the revenue distribution by price band. 

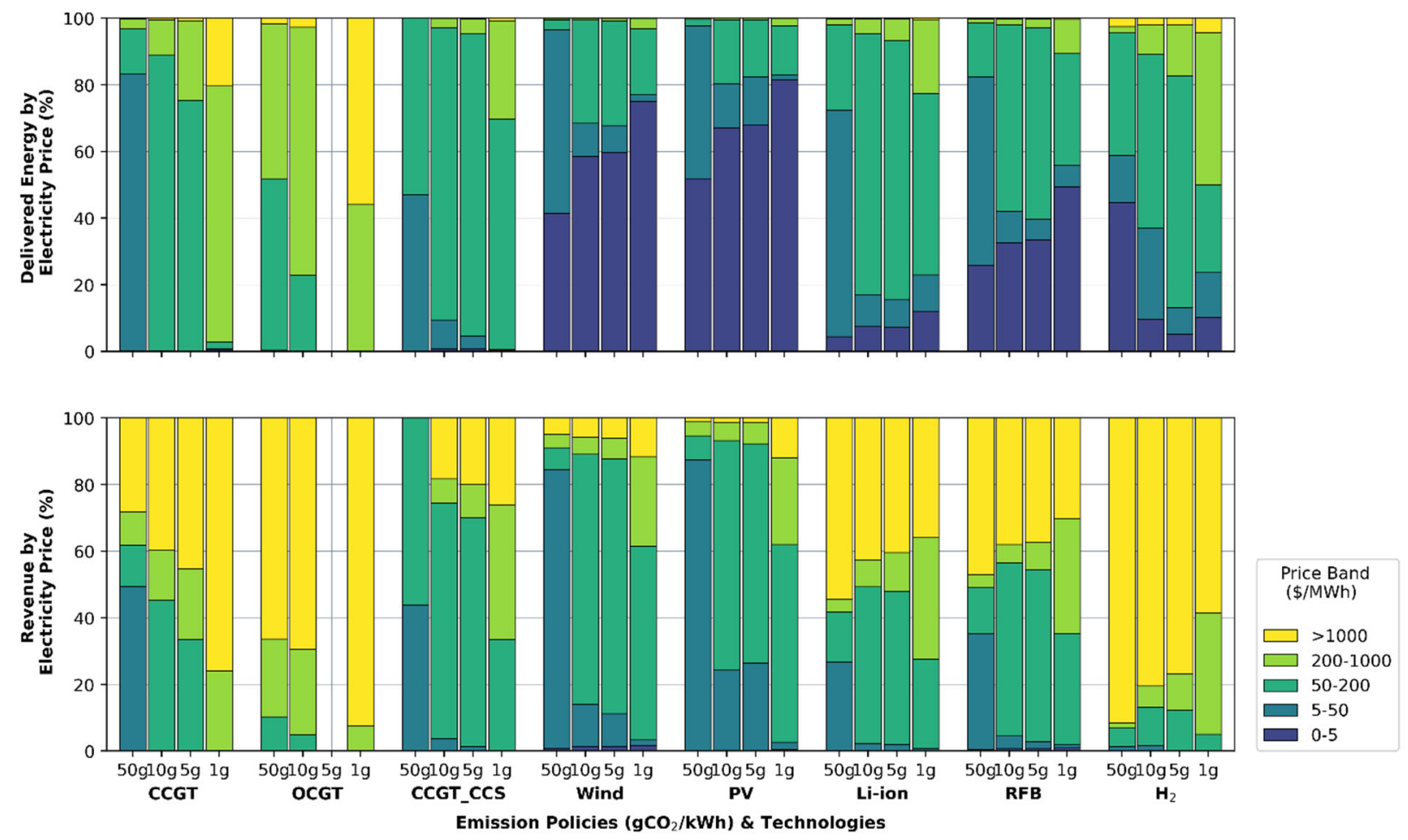

Figure S 7. Technology operation and revenue by price band for various resources under the Base +RFB +np-H2@\$10/kg scenario defined in Table 1. The upper panel shows the distribution of delivered energy by price band for different technologies and emission constraints. The lower panel shows the revenue distribution by price band. 